\title{
Effect of accelerated solvent extraction conditions on the isolation of bioactive compounds from fennel (Foeniculum vulgare Mill.) seeds
}

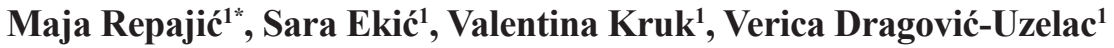 \\ ${ }^{1}$ Faculty of Food Technology and Biotechnology, University of Zagreb, Pierottijeva 6, 10000 Zagreb, Croatia \\ *Corresponding author: maja.repajic@pbf.unizg.hr
}

\begin{abstract}
This study focused to establish the optimal conditions of accelerated solvent extraction (ASE), i.e., temperature, static extraction time and number of extraction cycles, for the isolation of fennel (Foeniculum vulgare Mill.) seeds phenols and pigments using $96 \%$ ethanol as an extraction solvent. Hence, extraction conditions of temperature $\left(80\right.$ and $\left.110^{\circ} \mathrm{C}\right)$, static extraction time (5 and 10 min) and number of extraction cycle $(1,2,3$ and 4$)$ were varied. Obtained extracts were spectrophotometrically analyzed for the content of total phenols (TP), total chlorophylls (TCHL) and total carotenoids (TCAR). Applied extraction conditions had a significant $(p<0.01)$ influence on the yields of analyzed compounds, except for static extraction time on TCAR ( $p=0.11)$. Based on the results of statistical analysis, the highest levels of TP and TCHL were achieved at the most invasive conditions $\left(110^{\circ} \mathrm{C} / 10 \mathrm{~min} / 4\right.$ cycles), while shorter period was sufficient to reach the highest TCAR yield $\left(110^{\circ} \mathrm{C} / 5 \mathrm{~min} / 3 \mathrm{cycles}\right)$. In summary, ASE demonstrated to be effective extraction technique for the isolation of fennel seeds hydrophilic and lipophilic bioactive compounds.
\end{abstract}

Keywords: accelerated solvent extraction, fennel seeds, phenols, pigments, optimal conditions

\section{Introduction}

Fennel (Foeniculum vulgare Mill.) belongs to family Apiaceae and is annual or perennial plant with characteristic and strong flavor. It originates from Mediterranean region, but as cultivated, it is widely spread around the world (Badgujar et al., 2014), where different plant parts (leaves, young shoots, roots and seeds) have diverse applications in pharmaceutical, food, cosmetic and healthcare areas, but also as a traditional remedy (He and Huang, 2011). Fennel seeds are mostly known for their abundance with essential oil, thus are used as flavoring agents in various food products (Diao et al., 2014). Besides essential oils, fennel seeds are also rich in various hydrophilic and lipophilic compounds, e.g., phenols, chlorophylls, carotenoids, unsaturated fatty acids, phytosterols, etc. (Coşge et al., 2008; Rather et al., 2016; Islam et al., 2017; Mallik et al., 2020), which are known as strong antioxidants and are associated with the prevention of diseases as well as have an important role in human health (Araújo et al., 2011; Ciccone et al., 2013). Considering the extraction of plant bioactives, various conventional and advanced techniques are being used. Since conventional extraction techniques have serious disadvantages, e.g., they are time-consuming, use large solvent amounts and consequently raising pollution issues, and finally do not results with the sufficient yield (Wang and Weller, 2006), novel extraction approaches are favored, among which accelerated solvent extraction (ASE) is one of the most promising. Through the combination of elevated temperature and pressure, shortening of the extraction time and lower solvent consumption, easy handling, being automated (Wang and Weller, 2006; Mottaleb and Sarker, 2012) and providing high extraction yields (Repajić et al., 2020), ASE manifests as very effective and environment-friendly technique. However, since the main challenge during extraction of target compounds is to achieve their highest yields, it is of a great importance to select the optimal extraction conditions.

Hence, this study examined the influence of temperature (80 and 110 ${ }^{\circ} \mathrm{C}$ ), static extraction time (5 and $10 \mathrm{~min}$ ) and number of extraction cycle (1, 2, 3 and 4) on the yields of total phenols (TP), total chlorophylls (TCHL) and total carotenoids (TCAR) during "green" ASE of fennel seeds with $96 \%$ ethanol.

\section{Materials and methods}

\section{Plant material}

Dry bitter fennel (Foeniculum vulgare Mill.) seeds were procured from Harissa d.o.o. (Zagreb, Croatia). Seeds were ground using a commercial grinder (GT11, Tefal, Rumilly, France) and obtained powder was immediately used for the extraction.

\section{Extraction conditions}

For the extraction of fennel seeds phenols and pigments, ASE was performed on Dionex ${ }^{\mathrm{TM}}$ ASETM 350 Accelerated Solvent Extractor (Thermo Fisher Scientific Inc., Sunnyvale, CA, USA). Extraction procedure was set as follows: $3 \mathrm{~g}$ of the sample mixed with $2 \mathrm{~g}$ of diatomaceous earth was placed in $34 \mathrm{~mL}$ stainless steel cells fitted with 2 cellulose filters (Dionex ${ }^{\mathrm{TM}}$ 350/150 Extraction Cell Filters, Thermo Fisher Scientific Inc., Sunnyvale, CA, USA) at the bottom of the cell. In order to determine extraction conditions for obtaining the highest yields of target compounds, extraction conditions of temperature (80 and 110 $\left.{ }^{\circ} \mathrm{C}\right)$, static extraction time (5 and $10 \mathrm{~min}$ ) and number of extraction cycle $(1,2,3$ and 4$)$ were varied (Table 1). Fixed parameters were: $10.34 \mathrm{MPa}$, $30 \mathrm{~s}$ of purge with nitrogen and $50 \%$ of flushing. Obtained extracts were made up to volume in $50 \mathrm{~mL}$ volume flask with the extraction solvent (96\% ethanol). All extracts were performed in two replicates $(n=2)$.

\section{Determination of total phenols}

TP content was determined using Folin-Ciocalteau method described by Repajić et al. (2018). Briefly, a mixture of $100 \mu \mathrm{L}$ of sample, 200 $\mu \mathrm{L}$ of Folin Ciocalteu's reagent, $2 \mathrm{~mL}$ of distilled water and $1 \mathrm{~mL}$ of sodium carbonate solution $(1: 4, w / v)$ was incubated at $50^{\circ} \mathrm{C} / 25 \mathrm{~min}$. The absorbance was measured against the blank (extraction solvent) at $765 \mathrm{~nm}$. Calibration curve was obtained using gallic acid $\left(5 \mathrm{mg} \mathrm{mL} \mathrm{mL}^{-1}\right)$ and TP were expressed as $\mathrm{mg}$ of gallic acid equivalents (GAE) $100 \mathrm{~g}^{-1}$ of the sample. 


\section{Determination of total chlorophylls and carotenoids}

Content of pigments was determined according to Lichtenthaler and Buschmann (2001) at the following wavelengths: 648.6 and $664.1 \mathrm{~nm}$ for chlorophylls and $470 \mathrm{~nm}$ for carotenoids (according to the used extraction solvent). The extraction solvent was used as a blank.

The content of chlorophylls and carotenoids was calculated using following equations:

$\mathrm{c}_{a}(\mu \mathrm{g} \mathrm{mL}-1)=13.36 \mathrm{~A}_{664.1}-5.19 \mathrm{~A}_{648.6}$

$\mathrm{c}_{b}\left(\mu \mathrm{g} \mathrm{mL} \mathrm{L}^{-1}\right)=27.43 \mathrm{~A}_{648.6}-8.12 \mathrm{~A}_{664.1}$

$\mathrm{c}_{(\mathrm{x}+\mathrm{c})}\left(\mu \mathrm{g} \mathrm{mL} \mathrm{L}^{-1}\right)=\left(1000 \mathrm{~A}_{470}-2.13 \mathrm{C}_{a}-97.64 \mathrm{C}_{b}\right) / 209$

( $A=$ apsorbance, $c_{a}=$ concentration of chlorophyll $a, c_{b}=$ concentration of chlorophyll $b, c_{(x+c)}=$ concentration of total carotenoids)

Chlorophyll $a$, chlorophyll $b$, TCHL $\left(\mathrm{c}_{a}+\mathrm{c}_{b}\right)$ and TCAR were expressed as $\mathrm{mg} 100 \mathrm{~g}^{-1}$ of the sample.

All spectrophotometric measurements were done in duplicate $(\mathrm{N}=4)$.

\section{Statistical analysis}

Obtained results were statistically analyzed using Statistica ver. 10.0 software (Statsoft Inc., Tulsa, USA). Multifactorial analysis of variance (MANOVA) was applied and the significant differences among samples were determined with Tukey's HSD test, while possible grouping of the samples was examined by Principal Component Analysis (PCA). The significance level set for all tests was $\mathrm{p} \leq 0.05$.

Table 1. Experimental setup for accelerated solvent extraction trials

\begin{tabular}{|c|c|c|c|}
\hline Sample & $\begin{array}{c}\text { Temperature } \\
\left({ }^{\circ} \mathrm{C}\right)\end{array}$ & $\begin{array}{l}\text { Static time } \\
(\mathrm{min})\end{array}$ & $\begin{array}{c}\text { Cycle } \\
\text { number }\end{array}$ \\
\hline 1 & \multirow{8}{*}{80} & \multirow{4}{*}{5} & 1 \\
\hline 2 & & & 2 \\
\hline 3 & & & 3 \\
\hline 4 & & & 4 \\
\hline 5 & & \multirow{4}{*}{10} & 1 \\
\hline 6 & & & 2 \\
\hline 7 & & & 3 \\
\hline 8 & & & 4 \\
\hline 9 & \multirow{8}{*}{110} & \multirow{4}{*}{5} & 1 \\
\hline 10 & & & 2 \\
\hline 11 & & & 3 \\
\hline 12 & & & 4 \\
\hline 13 & & \multirow{4}{*}{10} & 1 \\
\hline 14 & & & 2 \\
\hline 15 & & & 3 \\
\hline 16 & & & 4 \\
\hline
\end{tabular}

\section{Results and discussion}

This study involved the optimization of ASE conditions for the isolation of phenols and pigments from fennel seeds (Foeniculum vulgare Mill.). Accordingly, target compounds were extracted under different temperatures $\left(80\right.$ and $\left.110{ }^{\circ} \mathrm{C}\right)$, static extraction times (5 and $\left.10 \mathrm{~min}\right)$ and number of extraction cycles (1, 2, 3 and 4) with $96 \%$ ethanol, which is characterized by GRAS ("Generally Recognized as Safe") status, with low cost and low toxicity. Therefore, its use in the food industry is permitted and it is increasingly used as the most suitable substitute for conventional extraction solvents (Barba et al., 2016). Table 2 shows the concentrations of analyzed compounds in obtained extracts. Furthermore, in order to establish the optimal ASE conditions for the highest yields of fennel seeds bioactives, statistical analysis was conducted and obtained data are presented in Table 3 . 


\section{Influence of ASE conditions on the content of phenols}

The content of TP in fennel seeds was determined in a range of 145.27 $474.21 \mathrm{mg}$ GAE $100 \mathrm{~g}^{-1}$ with grand mean value of $290.70 \mathrm{mg}$ GAE 100 $\mathrm{g}^{-1}$ (Tables 2\&3). Obtained results are in accordance with the research of Roby et al. (2012), who performed maceration of fennel seeds at room temperature for $72 \mathrm{~h}$ and determined $3.0 \mathrm{mg} \mathrm{GAE} \mathrm{g}^{-1} \mathrm{~d} . \mathrm{m}$. of TP in obtained fennel seeds ethanol extract. Expectedly, the lowest TP content was determined at the initial conditions $\left(80^{\circ} \mathrm{C}, 5 \mathrm{~min}, 1\right.$ cycle), while the most exhaustive applied conditions $\left(110^{\circ} \mathrm{C} / 10 \mathrm{~min} / 4\right.$ cycles $)$ yielded the highest TP content (Table 2).

As presented in Table 3, extraction temperature significantly $(\mathrm{p}<0.01)$ influenced on TP, where content of TP was almost $45 \%$ higher at $110{ }^{\circ} \mathrm{C}$ when compared to $80{ }^{\circ} \mathrm{C}$. Since the solubility of analyte increases with the solvent temperature increase, the diffusion rate and mass transfer are enhanced and consequently the ASE efficiency is higher (Mottaleb and Sarker, 2012). Furthermore, TP content significantly $(p<0.01)$ differed upon static extraction time, where the application of longer static time resulted with $18 \%$ higher TP ( 5 min $v s .10 \mathrm{~min}$ ) (Table 3 ). This parameter must be carefully optimized, being minimal, but sufficient for adequate mass transfer (Alvarez-Rivera et al., 2020). Increase of the static extraction time at elevated temperatures also promotes the diffusion of analytes into the extraction solvent (Mottaleb and Sarker, 2012) and complete extraction of bioactive compounds potentially occurs due to the use of multiple cycles (Mustafa and Turner, 2011). Results of this study supported above-mentioned, since the highest TP yields were recorded at the highest number of cycles (4), at which yield of TP increased even for $60 \%$ in comparison with 1 cycle (Table 3 ). The purpose of the static cycle is to introduce a fresh solvent and thus maintain a favorable extraction balance (Mottaleb and Sarker, 2012).

From all of the above, it is evident that the increase of temperature, static extraction time and extraction cycle number significantly increased the yield of fennel seeds TP, where $110{ }^{\circ} \mathrm{C} / 10 \mathrm{~min} / 4$ cycles were the conditions that promoted the highest TP content.

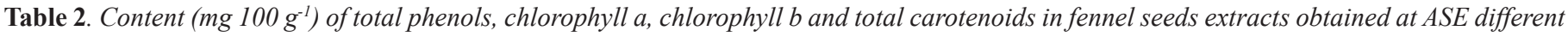
conditions

\begin{tabular}{|c|c|c|c|c|c|c|}
\hline Temperature $\left({ }^{\circ} \mathrm{C}\right)$ & $\begin{array}{l}\text { Static } \\
\text { time } \\
(\mathrm{min})\end{array}$ & $\begin{array}{l}\text { Cycle } \\
\text { number }\end{array}$ & $\begin{array}{l}\text { Total } \\
\text { phenols }\end{array}$ & Chlorophyll $a$ & Chlorophyll $b$ & $\begin{array}{l}\text { Total } \\
\text { carotenoids }\end{array}$ \\
\hline \multirow{8}{*}{80} & \multirow{4}{*}{5} & 1 & $145.27 \pm 8.07$ & $3.37 \pm 0.03$ & $1.80 \pm 0.07$ & $0.55 \pm 0.09$ \\
\hline & & 2 & $231.57 \pm 2.91$ & $6.21 \pm 0.07$ & $2.73 \pm 0.01$ & $1.85 \pm 0.16$ \\
\hline & & 3 & $223.80 \pm 0.21$ & $6.67 \pm 0.06$ & $2.79 \pm 0.13$ & $2.57 \pm 0.52$ \\
\hline & & 4 & $225.66 \pm 15.21$ & $7.33 \pm 0.04$ & $3.06 \pm 0.06$ & $2.73 \pm 0.74$ \\
\hline & \multirow{4}{*}{10} & 1 & $214.01 \pm 0.77$ & $6.13 \pm 0.00$ & $2.41 \pm 0.07$ & $2.51 \pm 0.24$ \\
\hline & & 2 & $217.83 \pm 6.28$ & $6.32 \pm 0.06$ & $2.60 \pm 0.08$ & $2.71 \pm 0.23$ \\
\hline & & 3 & $286.92 \pm 7.65$ & $7.47 \pm 0.03$ & $2.69 \pm 0.03$ & $4.29 \pm 0.68$ \\
\hline & & 4 & $357.73 \pm 17.10$ & $8.17 \pm 0.05$ & $3.36 \pm 0.06$ & $2.98 \pm 0.05$ \\
\hline \multirow{8}{*}{110} & \multirow{4}{*}{5} & 1 & $260.46 \pm 10.73$ & $5.84 \pm 0.08$ & $2.29 \pm 0.02$ & $2.95 \pm 0.35$ \\
\hline & & 2 & $345.83 \pm 5.57$ & $7.37 \pm 0.01$ & $3.15 \pm 0.03$ & $4.21 \pm 0.49$ \\
\hline & & 3 & $358.56 \pm 3.72$ & $7.65 \pm 0.00$ & $3.74 \pm 0.03$ & $3.85 \pm 0.25$ \\
\hline & & 4 & $340.46 \pm 20.57$ & $7.08 \pm 0.02$ & $3.12 \pm 0.01$ & $4.13 \pm 0.52$ \\
\hline & \multirow{4}{*}{10} & 1 & $248.98 \pm 11.27$ & $6.36 \pm 0.02$ & $2.94 \pm 0.01$ & $2.43 \pm 0.26$ \\
\hline & & 2 & $307.91 \pm 3.35$ & $7.33 \pm 0.06$ & $3.97 \pm 0.00$ & $3.28 \pm 0.14$ \\
\hline & & 3 & $412.00 \pm 0.62$ & $9.32 \pm 0.15$ & $4.84 \pm 0.05$ & $4.90 \pm 0.59$ \\
\hline & & 4 & $474.21 \pm 0.81$ & $8.99 \pm 0.02$ & $6.16 \pm 0.16$ & $1.70 \pm 0.05$ \\
\hline
\end{tabular}

$A S E=$ accelerated solvent extraction. Results are expressed as mean $\pm S D$.

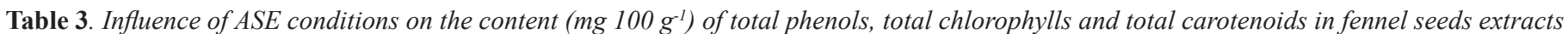

\begin{tabular}{|l|l|l|l|}
\hline Source of variation & $\begin{array}{l}\text { Total } \\
\text { phenols }\end{array}$ & $\begin{array}{l}\text { Total } \\
\text { chlorophylls }\end{array}$ & $\begin{array}{l}\text { Total } \\
\text { carotenoids }\end{array}$ \\
\hline Temperature $\left({ }^{\circ} \mathrm{C}\right)$ & $\mathrm{p}<0.01^{*}$ & $\mathrm{p}<0.01^{*}$ & $\mathrm{p}<0.01^{*}$ \\
\hline 80 & $237.85 \pm 2.35^{\mathrm{a}}$ & $9.14 \pm 0.02^{\mathrm{a}}$ & $2.52 \pm 0.10^{\mathrm{a}}$ \\
\hline 110 & $343.55 \pm 2.35^{\mathrm{b}}$ & $11.27 \pm 0.02^{\mathrm{b}}$ & $3.43 \pm 0.10^{\mathrm{b}}$ \\
\hline Static time $(\min )$ & $\mathrm{p}<0.01^{*}$ & $\mathrm{p}<0.01^{*}$ & $\mathrm{p}=0.11$ \\
\hline 5 & $266.45 \pm 2.35^{\mathrm{a}}$ & $9.28 \pm 0.02^{\mathrm{a}}$ & $2.86 \pm 0.10^{\mathrm{a}}$ \\
\hline 10 & $314.95 \pm 2.35^{\mathrm{b}}$ & $11.13 \pm 0.02^{\mathrm{b}}$ & $3.10 \pm 0.10^{\mathrm{a}}$ \\
\hline Cycle number & $\mathrm{p}<0.01^{*}$ & $\mathrm{p}<0.01^{*}$ & $\mathrm{p}<0.01^{*}$ \\
\hline 1 & $217.18 \pm 3.33^{\mathrm{a}}$ & $7.79 \pm 0.03^{\mathrm{a}}$ & $2.11 \pm 0.14^{\mathrm{a}}$ \\
\hline
\end{tabular}




\begin{tabular}{|l|l|l|l|}
\hline 2 & $275.78 \pm 3.33^{\mathrm{b}}$ & $9.92 \pm 0.03^{\mathrm{b}}$ & $3.01 \pm 0.14^{\mathrm{b}}$ \\
\hline 3 & $320.32 \pm 3.33^{\mathrm{c}}$ & $11.29 \pm 0.03^{\mathrm{c}}$ & $3.90 \pm 0.14^{\mathrm{c}}$ \\
\hline 4 & $349.51 \pm 3.33^{\mathrm{d}}$ & $11.82 \pm 0.03^{\mathrm{d}}$ & $2.88 \pm 0.14^{\mathrm{b}}$ \\
\hline Grand mean & $\mathbf{2 9 0 . 7 0}$ & $\mathbf{1 0 . 2 0}$ & $\mathbf{2 . 9 8}$ \\
\hline
\end{tabular}

$A S E=$ accelerated solvent extraction. Results are expressed as mean \pm SE. *Statistically significant variable at $p \leq 0.05$. Different letters within column mean statistically different values at $p \leq 0.05$.

\section{Influence of ASE conditions on the content of pigments}

Content of chlorophyll $a$ (CHL $a$ ) and $b$ (CHL $b$ ) ranged from 3.37 to

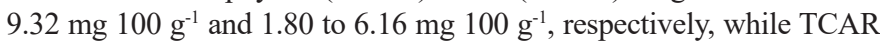
were in a range of $0.55-4.90 \mathrm{mg} 100 \mathrm{~g}^{-1}$ (Table 2). The grand mean values were 10.20 (TCHL) and 2.98 (TCAR) $\mathrm{mg} 100 \mathrm{~g}^{-1}$ (Table 3). As it can be seen, CHL $a$ was the predominant pigment, present in ratio of more than 2:1 in comparison with CHL $b$, what is characteristic for green plants (Alkema and Seager, 1982; Hojnik et al., 2007). Similar to the $\mathrm{TP}$, the lowest amounts of all pigments were found in extracts obtained at the starting ASE conditions $\left(80{ }^{\circ} \mathrm{C} / 8 \mathrm{~min} / 1\right.$ cycle $)$ and their highest yields were achieved at the same temperature and static extraction time as TP $\left(110^{\circ} \mathrm{C}, 10 \mathrm{~min}\right)$, but with lower cycle number ( 3 cycles), except for CHL $b$. Its highest yield was also achieved at the most exhaustive conditions applied, same as TP (Table 2).

Considering the influence of extraction parameters on the content of pigments, all examined parameters significantly $(\mathrm{p}<0.01)$ affected TCHL and TCAR, except for static extraction time on TCAR $(\mathrm{p}=0.11)$ (Table 3). Numerically, elevated temperature increased the yields of TCHL and TCAR for $23 \%$ and $36 \%$, respectively $\left(80^{\circ} \mathrm{C} v s .110^{\circ} \mathrm{C}\right)$. As mentioned above, longer static time did not cause significant changes in the amounts of TCAR, where yield increase was around $8 \%(5 \mathrm{~min} v s$. $10 \mathrm{~min}$ ). Thus, a shorter static extraction time ( $5 \mathrm{~min}$ ) could be preferred for the extraction of these compounds, therefore providing time- and energy-saving. Contrarily, increase of TCHL content during longer static extraction time was not negligible (20\%). In terms of cycle number, it can be observed that the highest increase of TCHL levels was recorded at the highest cycle number $(52 \%, 1 v s .4)$, while 3 extraction cycles were sufficient for the maximum TCAR yield $(85 \%, 1$ vs. 3). Since carotenoids are thermo-sensitive (Cha et al., 2010), longer extraction at the $110^{\circ} \mathrm{C}$ might caused the degradation of TCAR. Carotenoids are more sensitive to changes compared to the other pigments, which may be due to the linear and solid structure of carotenoid molecules, thus it is recommended among other things, to avoid prolonged processing time and heating at elevated temperature in order to decrease a loss of carotenoids (Britton and Khachik, 2009).

In summary, the highest examined ASE parameters positively affected chlorophylls' extraction, thus the highest levels of TCHL were obtained at $110^{\circ} \mathrm{C} / 10 \mathrm{~min} / 4$ cycles. Regarding the carotenoids, conditions of 110 ${ }^{\circ} \mathrm{C} / 5 \mathrm{~min} / 3$ cycles could be recommended as efficient for their isolation.

\section{PCA analysis}

In addition to MANOVA, PCA was performed in order to examine a possible grouping of the samples according to the applied ASE conditions and obtained results are shown in Figure 1.
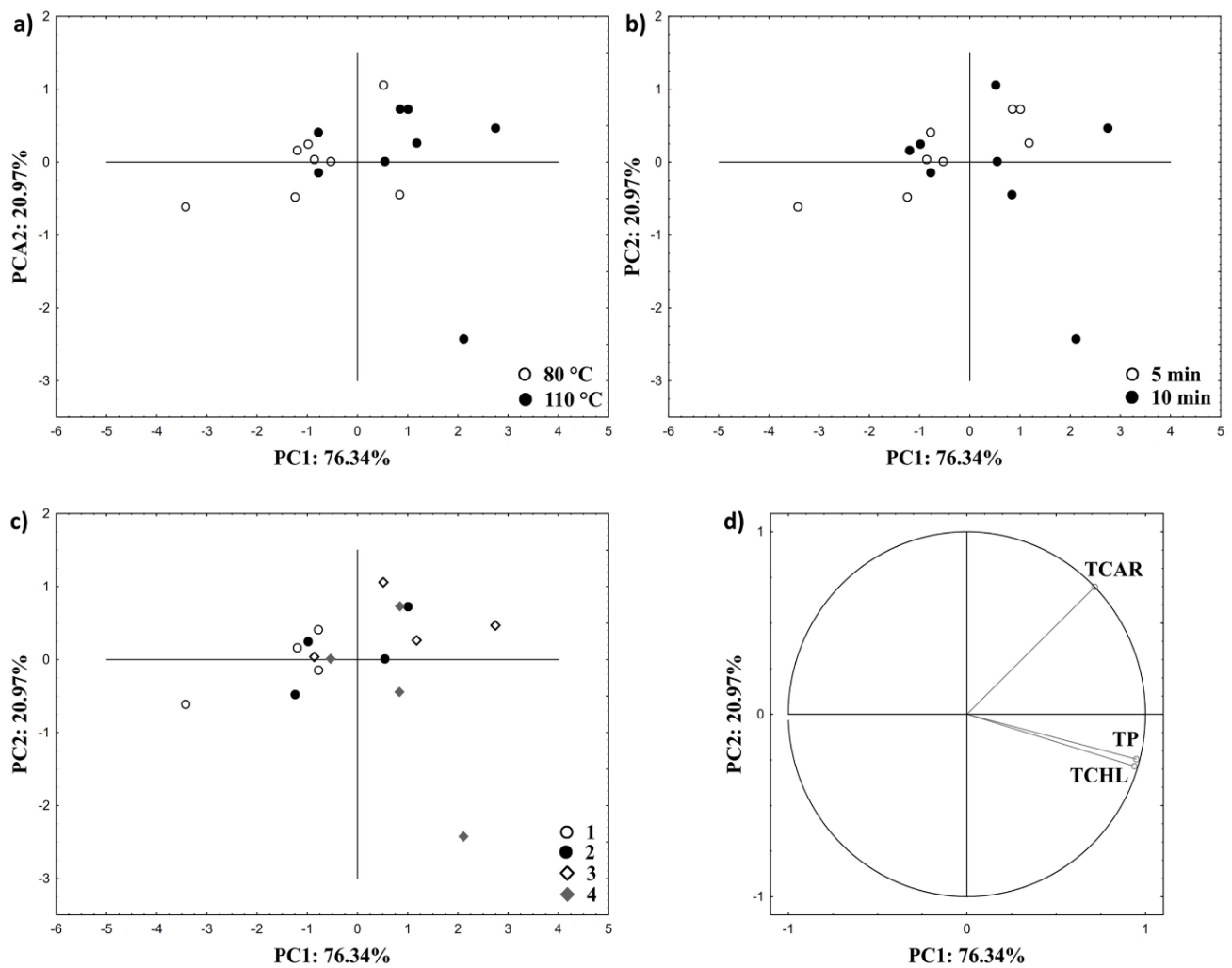

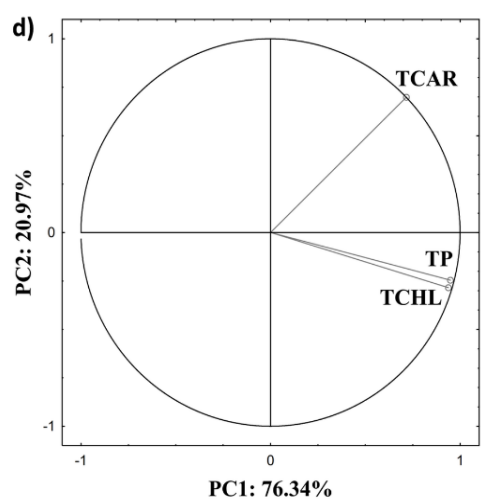

PC1: $76.34 \%$
Figure 1. Distribution of fennel seeds extracts in two-dimensional coordinate system defined by the first two principal components (PC1 and PC2) according to the
a) temperature;
b) static extraction time;
c) number of extraction cycles;
d) distribution of the variables in two-dimensional coordinate system defined by the first two principal components (PC1 and PC2)

$(T P=$ total phenols, $T C H L=$ total chlorophylls, TCAR=total carotenoids)

The mean values for each extract sample of all analyzed compounds were included in the analysis. 
Total variation of the analytical parameters is presented by the first two principal components (PC1 and PC2), which explained $97.31 \%$ of total variance (Fig. 1d). The PC1 attributed to $76.34 \%$ of total variance and it very strongly correlated with TP $(\mathrm{r}=0.95)$ and TCHL $(\mathrm{r}=0.94)$, while there was a strong correlation with TCAR $(\mathrm{r}=0.72)$. The PC2 accounted for $20.97 \%$ of total variance and it showed a strong correlation only with TCAR $(r=0.70)$. Considering the extraction temperature, almost all extracts obtained at $110{ }^{\circ} \mathrm{C}$ situated at positive values of $\mathrm{PC} 1$, while the majority of $80^{\circ} \mathrm{C}$ samples grouped at negative $\mathrm{PC} 1$ values of the biplot (Fig. 1a). A certain grouping of the samples occurred according to the applied static extraction time, where the most of 10 min-samples placed at the positive $\mathrm{PC} 1$ values and the most of samples obtained during $5 \mathrm{~min}$ of the static extraction time distributed at negative PC1 values (Fig. 1b). In Fig. 1c a relatively good separation of the samples regarding the cycle number can also be observed. The majority of samples obtained with 3 cycles and all 4 cycle-samples grouped at the positive $\mathrm{PC} 1$ values, while all samples obtained at lower cycle number (1) situated at the negative values of $\mathrm{PC} 1$.

\section{Conclusions}

The conducted research contributed to the definition of the optimal ASE conditions that allow the highest yields of target bioactive compounds, fennel seeds phenols and pigments, using 96\% ethanol as a "green" solvent. Results of statistical analysis revealed that conditions of 110 ${ }^{\circ} \mathrm{C} / 10 \mathrm{~min} / 4$ cycles stimulated the highest contents of polyphenols and chlorophylls, while the conditions of $110{ }^{\circ} \mathrm{C} / 5 \mathrm{~min} / 3$ cycles were sufficient for the extraction of carotenoids. Finally, ASE demonstrated to be effective extraction technique for the isolation of fennel seeds bioactives, providing high valuable extracts which could further have a potential application in the food, cosmetic or pharmaceutical industry as liquid or dry extracts.

Funding: This work was supported by the Croatian Science Foundation (grant number IP-01-2018-4924).

\section{References}

Alkema J., Seager S.L. (1982) The chemical pigments of plants. Journal of Chemical Education, 59 (3) 183. DOI: 10.1021/ed059p183 Alvarez-Rivera G., Bueno M., Ballesteros-Vivas D., Mendiola J.A., Ibanez E. (2020) Pressurized Liquid Extraction. In: POOLE, C.F., (Ed.), LiquidPhase Extraction, Elsevier Inc., Amsterdam/Oxford/Cambridge, pp. 375-394. DOI: 10.1016/B978-0-12-816911-7.00013-X

Araújo J.R., Gonçalves P., Martel F. (2011) Chemopreventive effect of dietary polyphenols in colorectal cancer cell lines. Nutrition Research, 31 (2) 77-87. DOI: 10.1016/j.nutres.2011.01.006

Badgujar S.B., Patel V.V., Bandivdekar A.H. (2014) Foeniculum vulgare Mill: a review of its botany, phytochemistry, pharmacology, contemporary application, and toxicology. BioMed Research International, 2014 1-32. DOI: 10.1155/2014/842674

Barba F.J., Zhu Z., Koubaa M., Sant'ana A.S., Orlien V. (2016) Green alternative methods for the extraction of antioxidant bioactive compounds from winery wastes and by-products: A review. Trends in Food Science and Technology, 49 96-109. DOI: 10.1016/j.tifs.2016.01.006

Britton G., Khachik F. (2009) Carotenoids in Food. In: Britton, G., Pfander, H., Liaaen-Jensen, S. (Eds.) Carotenoids. Carotenoids, Vol 5. Birkhäuser Basel. DOI: 10.1007/978-3-7643-7501-0_3

Cha K.H., Lee H.J., Koo S.Y., Song D.-G., Lee D.-U., Pan C.-H. (2010) Optimization of Pressurized Liquid Extraction of carotenoids and chlorophylls from Chlorella vulgaris. Journal of Agriculture and Food Chemistry, 58 793-797. DOI: 10.1021/jf902628j

Ciccone M.M., Cortese F., Gesualdo M., Carbonara S., Zito A., Ricci G., De Pascalis F., Scicchitano P., Riccioni G. (2013) Dietary intake of carotenoids and their antioxidant and anti-inflammatory effects in cardiovascular care. Mediators of Inflammation, DOI: 10.1155/2013/782137

Coşge B., Kiralan M., Gürbüz B. (2008) Characteristics of fatty acids and essential oil from sweet fennel (Foeniculum vulgare Mill. var. dulce) and bitter fennel fruits (F. vulgare Mill. var. vulgare) growing in Turkey. Natural Product Research, 22 (12) 1011-1016. DOI: 10.1080/14786410801980675 Diao W.R., Hu Q.P., Zhang H., Xu J.G. (2014) Chemical composition, antibacterial activity and mechanism of action of essential oil from seeds of fennel (Foeniculum vulgare Mill.). Food Control, 35 (1) 109-116. DOI: 10.1016/j.foodcont.2013.06.056

He W., Huang B. (2011) A review of chemistry and bioactivities of a medicinal spice: Foeniculum vulgare. Journal of Medicinal Plants Research, 5 (16) 3595-3600. DOI: 10.5897/JMPR.9000022

Hojnik M., Škerget M., Knez Ž. (2007) Isolation of chlorophylls from stinging nettle (Urtica dioica L.). Separation and Purification Technology, 57 37-46. DOI: 10.1016/j.seppur.2007.02.018

Islam M.A., Jeong B.G., Jung J., Shin E.C., Choi S.G., Chun J. (2017) Phytosterol determination and method validation for selected nuts and seeds. Food Analytical Methods, 10 (10) 3225-3234. DOI: 10.1007/s12161-017-0877-3

Lichtenthaler H.K., Buschmann C. (2001) Chlorophylls and carotenoids: Measurement and characterization by UV-VIS spectroscopy. Current Protocols in Food Analytical Chemistry, 1 (1) F4-3. DOI: 10.1002/0471142913.faf0403s01

Mallik S., Sharangi A.B., Sarkar T. (2020) Phytochemicals of Coriander, Cumin, Fenugreek, Fennel and Black Cumin: A Preliminary Study. National Academy Science Letters, 1-4. DOI: 10.1007/s40009-020-00884-5

Mottaleb M.A., Sarker S.D. (2012) Accelerated Solvent Extraction for Natural Products Isolation. In: Sarker, S.D., Nahar, L. (Eds.), Natural Products Isolation, Methods in Molecular Biology, 3rd ed., Springer, New York, NY, USA, pp. 75-88. DOI: 10.1007/978-1-61779-624-1_4

Mustafa A., Turner C. (2011) Pressurized liquid extraction as a green approach in food and herbal plants extraction: A review. Analytica Chimica Acta, 703 (1) 8-18. DOI: 10.1016/j.aca.2011.07.018

Rather M.A., Dar B.A., Sofi S.N., Bhat B.A., Qurishi M.A. (2016) Foeniculum vulgare: A comprehensive review of its traditional use, phytochemistry, pharmacology, and safety. Arabian Journal of Chemistry, 9 S1574-S1583. DOI: 10.1016/j.arabjc.2012.04.011

Repajić M., Cegledi E., Kruk V., Pedisić S., Çinar F., Bursać Kovačević D., Žutić I., Dragović-Uzelac V. (2020) Accelerated Solvent Extraction as a Green Tool for the Recovery of Polyphenols and Pigments from Wild Nettle Leaves. Processes, 8 (7) 803. DOI: 10.3390/pr8070803

Repajić M., Hajdinjak I., Lončarić P., Ivanković M., Dragović-Uzelac V., Levaj B. (2018) Stability of olive leaf drink upon storage at different temperatures. Glasnik zaštite bilja, 41 (5) 86-94. DOI: 10.31727/gzb.41.5.8

Roby M.H.H., Sarhan M.A., Selim K.A.-H., Khalel K.I. (2012) Antioxidant and antimicrobial activities of essential oil and extracts of fennel (Foeniculum vulgare L.) and chamomile (Matricaria chamomilla L.). Industrial Crops and Products, 44 437-445. DOI: 10.1016/j.indcrop.2012.10.012 Wang L., Weller C.L. (2006) Recent advances in extraction of nutraceuticals from plants. Trends in Food Science \& Technology, 17 (6) 300-312. DOI: 10.1016/j.tifs.2005.12.004 